\title{
Orchestrating Proactive and Reactive Mechanisms for Filtering Distracting Information: Brain-Behavior Relationships Revealed by a Mixed-Design fMRI Study
}

\author{
- Francesco Marini, ${ }^{1,4,5}$-Elise Demeter, ${ }^{1}$ Kenneth C. Roberts, ${ }^{1}$ - Leonardo Chelazzi, ${ }^{6,7}$ and Marty G. Woldorff ${ }^{1,2,3}$ \\ ${ }^{1}$ Center for Cognitive Neuroscience, Departments of ${ }^{2}$ Psychiatry and ${ }^{3}$ Psychology and Neuroscience, Duke University, Durham, North Carolina 27708, \\ ${ }^{4}$ Department of Psychology, University of Milano-Bicocca, Milan 20126, Italy, ${ }^{5}$ Department of Psychology, University of California, San Diego, California \\ 92093, ${ }^{6}$ Department of Neurological, Biomedical and Movement Science, University of Verona, Verona 37134, Italy, and ${ }^{7}$ Italian Institute of Neuroscience, \\ Verona 37134 , Italy
}

Given the information overload often imparted to human cognitive-processing systems, suppression of irrelevant and distracting information is essential for successful behavior. Using a hybrid block/event-related fMRI design, we characterized proactive and reactive brain mechanisms for filtering distracting stimuli. Participants performed a flanker task, discriminating the direction of a target arrow in the presence versus absence of congruent or incongruent flanking distracting arrows during either Pure blocks (distracters always absent) or Mixed blocks (distracters on $80 \%$ of trials). Each Mixed block had either $20 \%$ or $60 \%$ incongruent trials. Activations in the dorsal frontoparietal attention network during Mixed versus Pure blocks evidenced proactive (blockwise) recruitment of a distraction-filtering mechanism. Sustained activations in right middle frontal gyrus during $60 \%$ Incongruent blocks correlated positively with behavioral indices of distraction-filtering (slowing when distracters might occur) and negatively with distraction-related behavioral costs (incongruent vs congruent trials), suggesting a role in coordinating proactive filtering of potential distracters. Event-related analyses showed that incongruent trials elicited greater reactive activations in $20 \%$ (vs $60 \%$ ) Incongruent blocks for counteracting distraction and conflict, including in the insula and anterior cingulate. Context-related effects in occipitoparietal cortex consisted of greater target-evoked activations for distracter-absent trials (central-target-only) in Mixed versus Pure blocks, suggesting enhanced attentional engagement. Functional-localizer analyses in V1/V2/V3 revealed less distracter-processing activity in $60 \%$ (vs 20\%) Incongruent blocks, presumably reflecting tonic suppression by proactive filtering mechanisms. These results delineate brain mechanisms underlying proactive and reactive filtering of distraction and conflict, and how they are orchestrated depending on distraction probability, thereby aiding task performance.

Key words: attention; cognitive control; distraction filtering; flanker task; mixed-design fMRI

Significance Statement

Irrelevant stimuli distract people and impair their attentional performance. Here, we studied how the brain deals with distracting stimuli using a hybrid block/event-related fMRI design and a task that varied the probability of the occurrence of such distracting stimuli. The results suggest that when distraction is likely, a region in right frontal cortex proactively implements attentional control mechanisms to help filter out any distracting stimuli that might occur. In contrast, when distracting input occurs infrequently, this region is more reactively engaged to help limit the negative consequences of the distracters on behavioral performance. Our results thus help illuminate how the brain flexibly responds under differing attentional demands to engender effective behavior.

\section{Introduction}

Attentional control guides the selection of relevant sensory information and the exclusion of irrelevant and distracting stimuli.
The neural basis of selecting and processing target stimuli has been the focus of extensive research (for review, see Nobre and Kastner, 2014), but less is known about the neural basis of the data; F.M., E.D., L.C., and M.G.W. wrote the paper.

This work was supported by NIH Grants R01-MH060415 and R01-NS051048 to M.G.W. We thank Andrea Ravagli for helping collect data for a control experiment.
The authors declare no competing financial interests.

Correspondence should be addressed to Dr. Marty G. Woldorff, Center for Cognitive Neuroscience, Duke University, Box 90999, Durham, NC 27708-0999. E-mail: woldorff@duke.edu.

DOI:10.1523/JNEUROSCI.2966-15.2016

Copyright $\odot 2016$ the authors $\quad 0270-6474 / 16 / 360988-13 \$ 15.00 / 0$ 


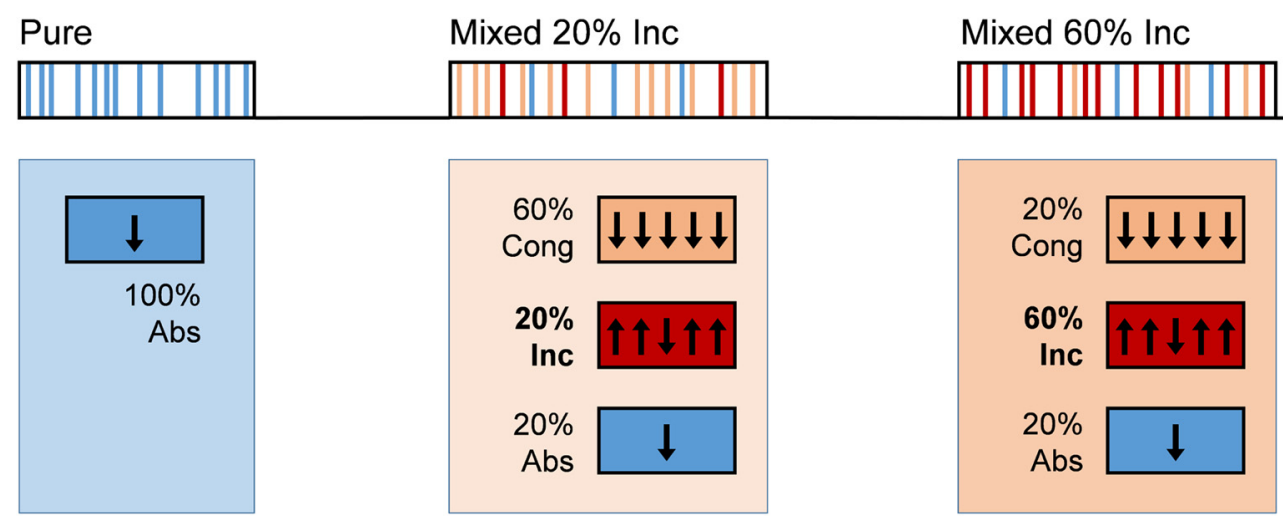

Figure 1. Hybrid block/event-related experimental design with the distraction context manipulation paradigm. The distraction context manipulation paradigm included three different types of blocks: (1) The Pure block, which consisted of all distracter-absent trials (Abs); (2) The Mixed 20\% Inc block, which consisted of 60\% congruent distracter trials (Cong), 20\% incongruent distracter trials (Inc), and 20\% distracter-absent trials (Abs); and (3) The Mixed 60\% Inc block, which consisted of 60\% congruent distracter trials (Cong), 20\% incongruent distracter trials (Inc), and 20\% distracter-absent trials (Abs). Before the beginning of each block, a visual cue informed participants about the type of the starting block (Pure, $20 \%$ Inc, or $60 \%$ Inc). Within each block, trials were jittered with interstimulus intervals ranging from 1.5 to $9 \mathrm{~s}$.

suppression of distracting stimuli (for review, see Geng, 2014). Distracters can be suppressed reactively, when a salient but irrelevant stimulus captures attention and its processing and behavioral impact need to be suppressed (Geng and DiQuattro, 2010; Gaspar and McDonald, 2014), or proactively, when the irrelevant stimulus features (Sawaki et al., 2012; Gaspar and McDonald, 2014), spatial location (Serences et al., 2004), or object types (Seidl et al., 2012) are known in advance, allowing control processes to direct attention away from those dimensions before stimulus appearance. Although reactive attentional control helps when an unanticipated distraction necessitates late adjustments of control (Jacoby et al., 1999; Purmann et al., 2009), proactive control operates on a wider timescale (Appelbaum et al., 2014) by preemptively modulating target-orienting and distractersuppressing processes, either trial-by-trial (Leber, 2010) or at the block level (akin to an attentional set).

In a flanker task, distracter suppression might consist of anticipatory attenuation of distracter-related activity before stimulus onset (Gulbinaite et al., 2014). Instantiation of proactive distraction-filtering on each trial, however, is costly for cognitive control, and may require some extra motivational incentives (such as reward) to be engaged (Marini et al., 2015). Moreover, when to-be-ignored distracters occur frequently, a sustained filtering mechanism can be implemented (i.e., proactively) throughout experimental blocks. Accordingly, two forms of proactive control of distraction can be distinguished: those that are implemented before an expected distraction, but not sustained across trials ("phasic" proactive control; Oliveira et al., 2014), and those that can be sustained across multiple trials (Braver et al., 2009; Marini et al., 2013; "tonic" proactive control). However, relatively limited work has specifically investigated such sustained distraction filtering (for reviews of proactive and reactive cognitive control, see Aron, 2011; Braver, 2012).

A recent set of behavioral studies introduced the distraction-context manipulation paradigm and identified a supramodal mechanism for filtering distracters (Marini et al., 2013). This distraction-filtering mechanism activates proactively and persistently throughout experimental blocks containing frequent distracters. Its activation typically entails a reaction time (RT) cost (distraction-filtering cost) on distracter-absent trials in blocks with frequent distracterpresent trials (Mixed blocks) relative to physically identical trials in blocks where distracters never occur (Pure blocks).
The behavioral hallmark of this distraction-filtering mechanism is an inverse correlation (Marini et al., 2013) between the distraction-filtering cost, reflecting top-down mechanisms to counteract potential distraction (Lavie, 2005; Sarter et al., 2006), and the conflict cost (slower RTs on incongruent versus congruent trials).

Here, we used a hybrid block/event-related fMRI design to characterize the neural basis and functional dynamics of distraction filtering. The overarching objective was to provide a coherent and comprehensive picture of proactive and reactive filtering processes, and to examine their engagement trade-off depending on the distracter-related context. The general hypothesis was that when conflicting distraction is likely, cognitive systems engage proactive filtering to cope with it, as evidenced behaviorally by the incursion of a distractionfiltering cost (Marini et al., 2013). Complementarily, when conflicting distraction is infrequent, mainly reactive filtering mechanisms are engaged, and only upon detection of actual conflict. Importantly, whereas the latter strategy reduces the ongoing burden on cognitive systems (no filtering cost), when conflict does occur it is dealt with less efficiently. We speculated that conflict likelihood in a given context would tip the balance toward one or the other strategy, although perhaps with individual differences.

Neurally, we hypothesized that in Mixed versus Pure blocks proactive distraction filtering would engage increased sustained activity in the frontoparietal attention network (Corbetta and Shulman, 2002), particularly in the right middle frontal gyrus (rMFG; Corbetta et al., 2008; McNab and Klingberg, 2008; Demeter et al., 2011). In contrast, we expected that reactive distraction filtering would engage conflict-detection regions in medial-frontal and insular cortex (Casey et al., 2000; Durston et al., 2003; Wager et al., 2005) and modulate transient rMFG activity, mainly in blocks with no proactive filtering (i.e., rare-conflict blocks). Furthermore, we anticipated that correlative relationships between sustained control-related brain activity and behavioral measures of filtering and conflict in frequent-conflict blocks may be observed Finally, we assessed how distraction-filtering mechanisms may be implemented in occipitoparietal cortex during attentional engagement and sensory processing, specifically predicting greater sensory suppression of distracters during blocks with a relatively high (vs low) likelihood of conflict. 


\begin{abstract}
Materials and Methods
Participants

Twenty participants took part in the study (mean age \pm SD: $26.2 \pm 4.3$ years, range $18-$ 35,10 females, all right-handed). One additional participant was excluded from analysis because of excessive sleepiness during the experiment. Participants had normal or corrected-to-normal vision, normal hearing, and did not report any history of psychiatric or neurological disorders. Participants gave their written informed consent to participate in the study in accordance with the Duke Institutional Review Board and were compensated $\$ 20 / \mathrm{h}$ for their participation.
\end{abstract}

\section{Experimental procedure}

Behavioral task. Participants performed an arrow-flanker task (Eriksen and Eriksen, 1974; Ridderinkhof et al., 2002) where they discriminated the orientation (up or down) of a central target arrow. On distracter-absent trials, the target arrow was presented by itself. On distracter trials, four distracting arrows ( 2 on each side) flanked the target arrow. The distracting arrows could be congruent or incongruent in orientation relative to the central target arrow. Visual stimuli were programmed using MATLAB R2013a (MathWorks) with Psychtoolbox 3.0 (Kleiner et al., 2007). Stimuli were presented for $200 \mathrm{~ms}$ in black on a mediumgray background. Each arrow subtended a visual angle of $0.75^{\circ}$ (vertically) by $0.5^{\circ}$ (horizontally), with a center-to-center distance between adjacent arrows of $0.75^{\circ}$. Participants were instructed to respond as quickly and accurately as possible by pressing the button corresponding to the orientation of the target arrow, while ignoring any distracting arrows (right index and middle fingers used for responses; up/down assignment to fingers counterbalanced across participants). Responses were collected through an MR-compatible button-box device (Current Design).

The experiment included three block types: (1) Pure blocks, consisting of all distracterabsent trials (Abs_Pure); (2) Mixed 20\% Incongruent blocks (20\% Inc), consisting of $60 \%$ trials with congruent flanking arrows, $20 \%$ trials with incongruent flanking arrows, and 20\% distracter-absent trials; and (3) Mixed 60\% Incongruent blocks (60\% Inc), consisting of $60 \%$ trials with incongruent flanking arrows, 20\% trials with congruent flanking arrows, and 20\% distracter-absent trials (Fig. 1). Stimulus sequences and trial timings were pseudorandomized, with stimulus onset asynchronies jittered between 1.5 and $9.0 \mathrm{~s}$ using a genetic algorithm procedure (Optimize GA; Wager and Nichols, 2003). Before the beginning of each block, participants were visually cued about the type of block that was about to start.

fMRI acquisition. MR images were collected on a 3T GE MR750 scanner with an eight-channel head coil. Functional images were acquired with a $2^{*}$-weighted pulse sequence using spiral sensitivity encoding (SENSE) with the parameters: horizontal FOV $=19.2 \mathrm{~cm}$, vertical $\mathrm{FOV}=13.6 \mathrm{~cm}, \mathrm{TE}=28 \mathrm{~ms}, \mathrm{TR}=1500 \mathrm{~ms}$, flip angle $75^{\circ}$. The resulting voxel size was $3 \times 3 \times 4 \mathrm{~mm}$ with no slice gap. Anatomical series were acquired at both the same resolution as the functional images (coplanar) and at higher resolution (voxel size $1 \times 1 \times 1 \mathrm{~mm}$; horizontal FOV 25.6

\section{Distracter-Absent}

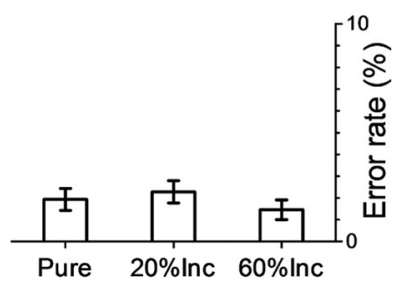

-Present congruent $\square$ incongruent
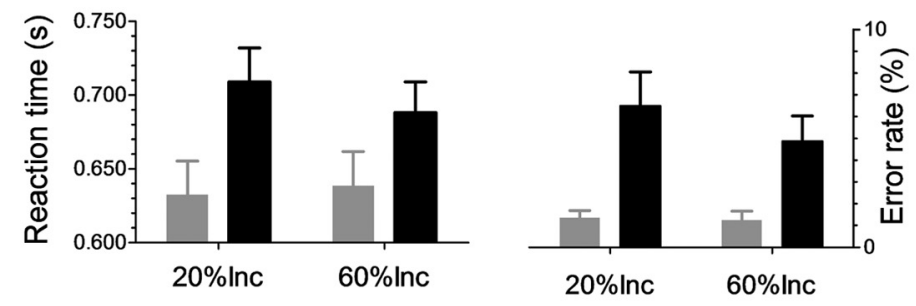

c Filtering Cost vs. Conflict Cost
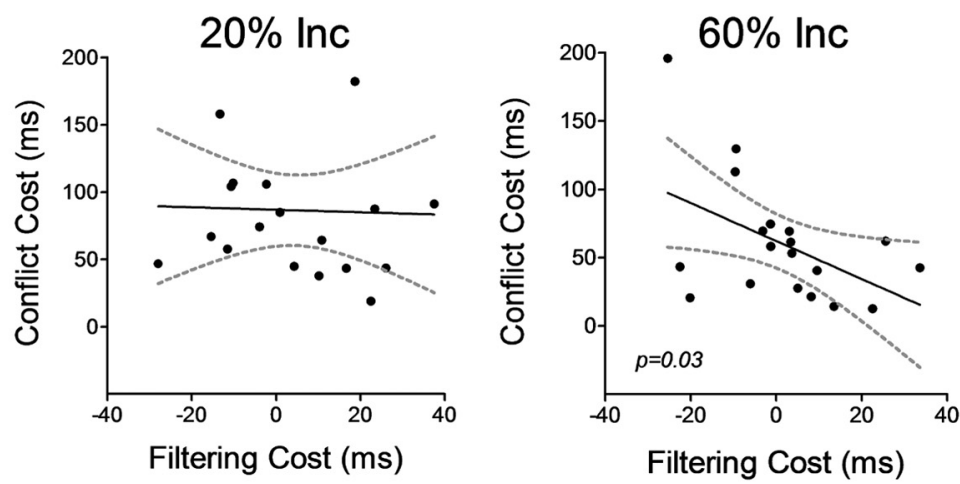

Figure 2. Behavioral measures of distracter filtering and of distracter interference. $\boldsymbol{A}, \mathrm{RT}$ (in seconds, on the left side) and error rate (in percentage, on the right side) for distracter-absent stimuli. No significant main effects were observed in RTs or in Error rates between the Pure block, the $20 \%$ Incongruent block ( $20 \%$ Inc), and the $60 \%$ Incongruent ( $60 \%$ Inc) block. Error bars represent the SEM across subjects within each condition. $\boldsymbol{B}, \mathrm{RT}$ (in seconds, on the left side) and error rate (in percentage, on the right side) for targets accompanied by distracters. Responses were overall faster and more accurate for congruent trials compared with incongruent trials. The Conflict cost (incongruent minus congruent, for both distracter RTs and error rates) was larger in the 20\% Incongruent block ( $20 \%$ Inc) than in the $60 \%$ Incongruent block (60\% Inc). Error bars represent the SEM across subjects. C, Linear regression analysis, across subjects, between the Filtering cost (horizontal axis) and the Conflict cost (vertical axis). A significant inverse correlation emerged in the $60 \%$ Inc block (right graph), indicating that subjects who engaged a distraction filtering mechanism to a greater extent, as indicated by a larger Filtering cost, were more efficient in limiting distracter interference in this condition, as indicated by a smaller Conflict cost. This relationship was not observed in the $20 \%$ Inc blocks. Dashed curves represents $95 \%$ confidence intervals . 
Table 1. Brain regions that showed peaks of sustained activity in Mixed blocks compared to Pure blocks

\begin{tabular}{rllllrlll}
\hline CL-size & CL-p & Z value & $X$ & $Y$ & $Z$ & Side & Region & Area \\
\hline 15586 & $<10^{-10}$ & 4.4 & -34 & -54 & 54 & $\mathrm{~L}$ & Superior parietal lobule & BA 7 \\
15586 & $<10^{-10}$ & 3.99 & -22 & -72 & 50 & $\mathrm{~L}$ & Precuneus & BA 7 \\
15586 & $<10^{-10}$ & 3.94 & -4 & -72 & 46 & $\mathrm{~L}$ & Precuneus & BA 7 \\
15586 & $<10^{-10}$ & 3.94 & -60 & -54 & -8 & $\mathrm{~L}$ & Middle temporal gyrus & BA 37 \\
15586 & $<10^{-10}$ & 3.94 & -42 & -56 & -14 & $\mathrm{~L}$ & Fusiform gyrus & BA 37 \\
3041 & $<0.001$ & 3.71 & -52 & 24 & 26 & $\mathrm{~L}$ & Inferior frontal gyrus & BA 9 \\
3041 & $<0.001$ & 3.65 & -46 & 20 & 34 & $\mathrm{~L}$ & Middle frontal gyrus & BA 9 \\
3041 & $<0.001$ & 3.65 & -44 & 28 & 18 & $\mathrm{~L}$ & Middle frontal gyrus & BA 46 \\
3041 & $<0.001$ & 3.57 & -28 & 64 & 2 & $\mathrm{~L}$ & Middle frontal gyrus & BA 10 \\
3041 & $<0.001$ & 3.44 & -54 & 20 & 4 & $\mathrm{~L}$ & Inferior frontal gyrus & BA 45 \\
3041 & $<0.001$ & 3.43 & -52 & 24 & 2 & $\mathrm{~L}$ & Inferior frontal gyrus & BA 45 \\
1426 & $<0.05$ & 3.56 & 54 & 40 & 18 & $\mathrm{R}$ & Middle frontal gyrus & BA 46 \\
1426 & $<0.05$ & 3.48 & 32 & 34 & 32 & $\mathrm{R}$ & Middle frontal gyrus & BA 9 \\
1426 & $<0.05$ & 3.29 & 24 & 32 & 38 & $\mathrm{R}$ & Middle frontal gyrus & BA 8 \\
1426 & $<0.05$ & 3.19 & 54 & 40 & 22 & $\mathrm{R}$ & Middle frontal gyrus & BA 46 \\
1426 & $<0.05$ & 3.18 & 8 & 38 & 40 & $\mathrm{R}$ & Medial frontal gyrus & BA 8 \\
1426 & $<0.05$ & 3.14 & 14 & 34 & 44 & $\mathrm{R}$ & Medial frontal gyrus & BA 8 \\
\hline
\end{tabular}

Cluster size (CL-size) is expressed in voxels and the reported $p$ values are FWER-corrected with the cluster method $(\mathrm{CL}-\mathrm{p})$. Coordinates are in MNI space and BA labels refer to the nearest grey matter (within $5 \mathrm{~mm}$ of the peak coordinates).

Fifteen seconds of fixation were presented between blocks. To help keep participants alert, participants were asked to press a button when a central fixation point changed briefly from black to light gray (once per arrow-task or fixation block).

\section{Behavioral data analyses}

Behavioral analyses focused on the effects of distraction filtering and conflict on RT and accuracy (all behavioral analyses were also conducted using the Inverse Efficiency score and yielded the same results as compared with the analysis of RT and accuracy separately). Based on previous findings (Marini et al., 2013), we hypothesized that participants' responses would be slower for distracter-absent trials during the Mixed blocks than for the identical distractor-absent trials in the Pure blocks, reflecting the behavioral cost (filtering cost) of setting up a mechanism to help filter out the distracting arrows present on most trials in the Mixed blocks. A key finding of the previous study (Marini et al., 2013) was that the filtering cost was inversely correlated, across subjects, with the behavioral cost observed on incongruent distracter trials relative to congruent distracter trials (conflict cost). In the regression analyses, and in accordance with the previous study (Marini et al., 2013), to discount any speed-accuracy tradeoff in the subjects' performance, we used the inverse efficiency (IE) score, which is calculated as the RT divided by the accuracy (Townsend and Ashby, 1983). We thus calculated the filtering cost and the conflict cost using the following formulae:

$$
\begin{aligned}
& \text { Filtering } \operatorname{Cost}_{20 \% \text { Inc }}=\frac{\left(\text { medianIE }_{\text {Abs_20\% Inc }}-\text { medianIE }_{\text {Abs_Pure }}\right)}{\left(\text { medianIE }_{\mathrm{Abs}_{\_} 20 \% \text { Inc }}+\text { medianIE }_{\text {Abs_Pure }}\right)}
\end{aligned}
$$

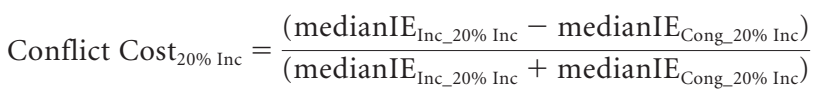

$$
\begin{aligned}
& \text { Filtering } \text { Cost }_{60 \% \text { Inc }}=\frac{\left(\text { medianIE }_{\text {Abs_60\% Inc }}-\text { medianIE }_{\text {Abs_Pure }}\right)}{\left(\text { medianIE }_{\text {Abs_60\% Inc }}+\text { medianIE }_{\text {Abs_Pure }}\right)} \\
& \text { Conflict } \operatorname{Cost}_{60 \% \text { Inc }}=\frac{\left(\text { medianIE }_{\text {Inc_60\% Inc }}-\text { medianIE }_{\text {Cong_60\% Inc }}\right)}{\left(\text { medianIE }_{\text {Inc_60\% Inc }}+\text { medianIE }_{\text {Cong_60\% Inc }}\right)}
\end{aligned}
$$

RTs faster than $200 \mathrm{~ms}$ and slower than an upper cutoff value (calculated with the quartile method; Ratcliff, 1993), were excluded from the analysis. In the regression analysis, the possible presence of outliers was evaluated with the Bonferroni method (Fox, 1997) as implemented in the R software package (R Core Team, 2015). Statistical analyses on the behavioral data were performed by means of planned comparisons with paired-samples $t$ tests and with general linear regression models. The familywise error rate (FWER) was controlled at significance level $\alpha=0.05$ by applying the Holm-Bonferroni correction (Holm, 1979).

\section{fMRI data analysis}

Analyses were conducted with the FSL 5.0.1 software package (FMRIB's Software Library; Smith et al., 2004).

Data preprocessing. Functional images were corrected for interleaved slice acquisition, prewhitened using FILM (FMRIB's Improved Linear Modeling), spatially smoothed with a three-dimensional Gaussian kernel (FWHM: $8 \mathrm{~mm}$ for task runs and $5 \mathrm{~mm}$ for the retinotopic localizer run), and corrected for head motion with the FLIRT tool (Jenkinson et al., 2002). A high-pass filter with a cutoff of 215 s was applied. Functional images were coregistered to the high-resolution anatomical image and then standardized to the Montreal Neurological Institute (MNI) $2 \mathrm{~mm}$ template using FLIRT. For the localizer run and the visual region-ofinterest (ROI) analyses, a mask was applied to exclude voxels outside the occipital lobe. The occipital lobe mask was created on the MNI $2 \mathrm{~mm}$ template with the WFU Pickatlas (Maldjian et al., 2003) and then transposed into the single-subject lower-resolution fMRI anatomical space.

Exploratory whole-brain analysis. Analysis was performed with the general linear model implemented in FEAT (FMRIB's Expert Analysis Tool) with custom regressors. A mixed block/event-related design was used (Visscher et al., 2003; Petersen and Dubis, 2012). Sustained (blockrelated) activity was modeled by entering boxcar-shaped regressors (Pure, 20\% Inc, 60\% Inc), including the temporal derivative. Transient (event-related) activity was modeled by using a finite impulse-response (FIR) model (Dale, 1999; Ollinger et al., 2001; Visscher et al., 2003). The seven event types (identified with the following abbreviations TrialType_BlockType: Abs_Pure, Abs_20\% Inc, Cong_20\% Inc, Inc_20\% Inc, Abs_60\% Inc, Cong_60\% Inc, Inc_60\% Inc) were modeled with 10 time points, $1.5 \mathrm{~s}$ apart (i.e., the TR), starting $3 \mathrm{~s}$ before stimulus onset and terminating $10.5 \mathrm{~s}$ after onset. Motion estimates were included as nuisance regressors in the statistical model.

Contrasts of interest compared blocks with different distraction probability and conflict level with respect to: (1) sustained activity (Mixed blocks vs Pure blocks), (2) event-related conflict-evoked activity (incongruent trials vs congruent trials), and (3) event-related target-evoked activity in absence of distraction (distracter-absent trials of Pure blocks vs distracter-absent trials of Mixed blocks). Results of the analysis of conflict-evoked and target-evoked activity were calculated on the average BOLD signal of three peri-peak time points of the FIR model corresponding to the interval 3-6 s after stimulus onset. Group analyses were performed implementing a mixed-effects model in FEAT with FLAME (FMRIB's Local Analysis of Mixed Effects). Statistical images were corrected for FWER by using a cluster-based correction. Clusters of activations were individuated by thresholding the $Z$-stat images at $Z>2.33$ and then a cluster-size correction was used with threshold $p=0.05$ (corrected).

A priori frontal ROI analyses. To further investigate proactive distraction filtering, a ROI analysis was conducted in the rMFG. Previous work has indicated that this region is particularly sensitive to increased attentional control demands brought on by distraction (Demeter et al., 2011). Here, we hypothesized that proactive (sustained) activity in the rMFG may be sensitive to the increased demands brought on by the higher probability for conflicting distracters in the $60 \%$ Inc condition. Values from the contrasts on the parameter estimates from the Pure and Mixed blocks were extracted for each subject from a spherical ROI centered in the rMFG (6 mm radius, MNI coordinates: 36, 10, 34; based on Demeter et al., 2011).

Reactive (transient) responses to incongruent distracters, which we hypothesized would be stronger when conflict occurs only rarely, were investigated with an analysis including the rMFG ROI, as well as ROIs in anterior cingulate cortex (ACC) and in bilateral insula based on previous work that isolated specific responses for incongruent flanker stimuli in these regions (Wager et al., 2005; MNI coordinates: ACC: 6, 12, 46; insula: $30,20,2$, and $-30,24,-2$; ROIs were $6 \mathrm{~mm}$ radius spheres centered within $6 \mathrm{~mm}$ from peak activation coordinates by Wager et al., 2005). We extracted values from the event-related contrasts on the pa- 


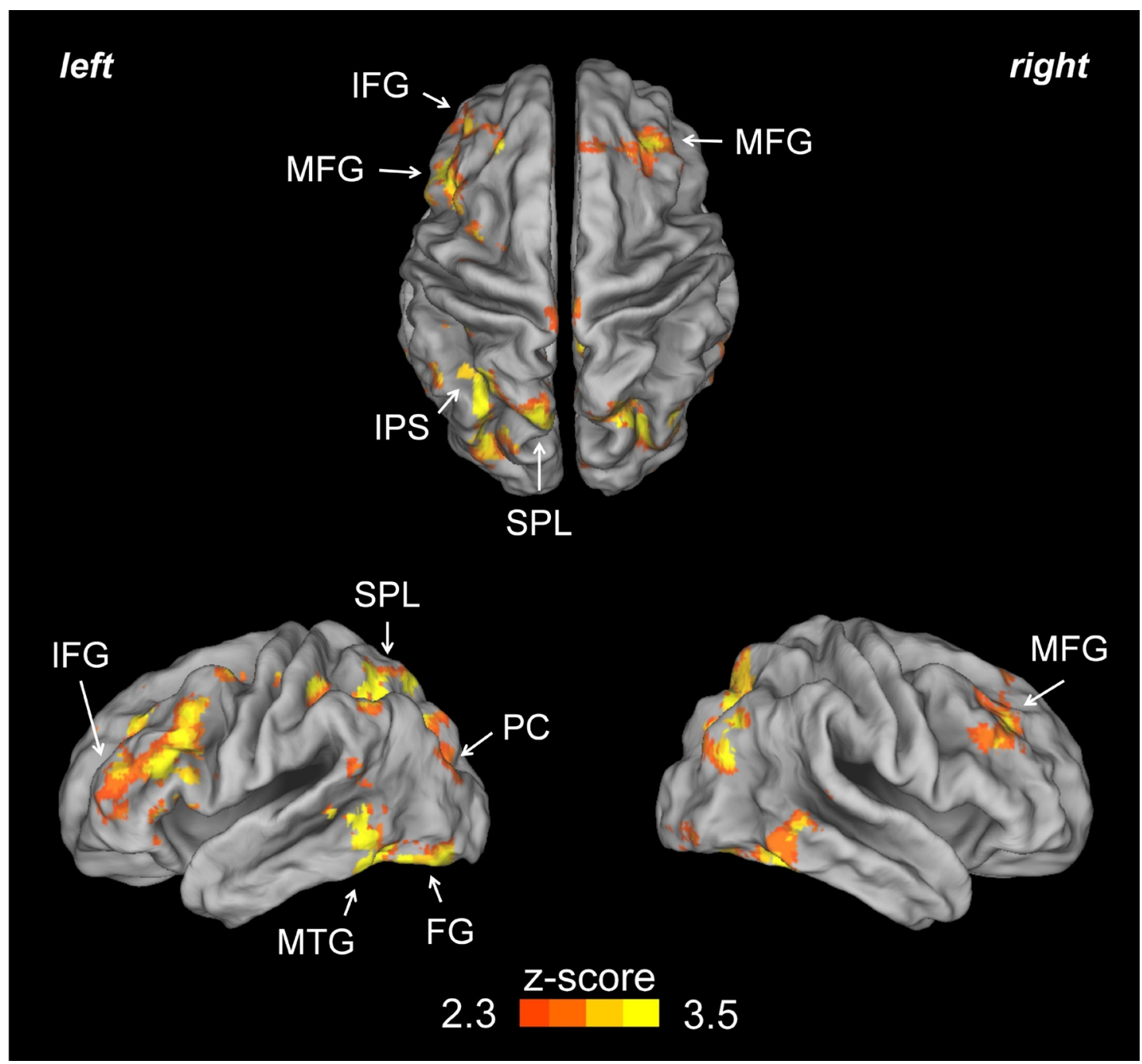

Figure 3. Sustained brain activity in Mixed blocks minus Pure blocks reflects proactive control in frontoparietal networks. In contexts with potential distraction and conflict, sustained brain activations were observed in a widespread set of brain regions, including the frontoparietal attentional network. These activations likely indicate the proactive recruitment of attentional control mechanisms, likely related to distracter filtering and/or focusing of processing resources on targets. Peaks of activity were identified in IFG, MFG, SPL, IPS, precuneus (PC), FG, and MTG.

rameter estimates from the incongruent versus congruent trials from the $20 \%$ Inc and $60 \%$ Inc blocks.

Localizer run analysis. Data from the localizer run were analyzed with a block-design statistical model to identify ROIs in the visual cortex representing distracters but not targets (from the contrast distracters block $>$ target block) and those representing targets but not distracters (from the contrast target block $>$ distracter block).

Visual cortex ROI analyses. We conducted a voxelwise analysis within the target and distractor ROIs identified by the localizer run to investigate whether the probability of conflicting distraction within a block modulated the sensory evoked responses to the distractor and to the target stimuli. The voxelwise analysis within the functional ROIs in visual areas used a small-volume correction with the cluster-based method $(Z>$ 1.65 , corrected $p<0.05$ ). Functional data were then mapped onto an inflated representation of the retinotopic visual cortex with PALS-B12 human atlas and Caret5 software (Van Essen, 2005). An additional analysis within functional ROIs in the visual cortex was performed that aimed at separating distracter-related activations in response to incongruent and congruent trials, for the $20 \%$ Inc and the $60 \%$ Inc block, respectively. This analysis used an uncorrected threshold of $p<0.01$. Finally, an across-subjects correlation analysis was conducted between distracterrelated regions of the visual cortex and the attentional control ROI in the rMFG. Mean values of parameter estimates for incongruent minus congruent distracter stimuli, separately for the $20 \%$ Inc and for the $60 \%$ Inc blocks, were extracted from a small spherical ROI in V4 (radius $4 \mathrm{~mm}$, centered on the peak location; MNI coordinates: $-26,-76,-20$; identified in the previous analysis of incongruent vs congruent trials) and from the rMFG ROI. We then calculated for each subject the increase in brain response in the $20 \%$ Inc blocks, relative to $60 \%$ Inc blocks, for incongruent distracter stimuli, both in the V4 ROI and in the rMFG ROI. This relative increase in brain response in $20 \%$ Inc blocks was calculated for each subject by means of a subtraction of individual mean values of parameter estimates for the contrast "incongruent $>$ congruent distracter" in the $20 \%$ Inc block minus values for the same contrast in the $60 \%$ Inc block. The resulting values were used for conducting a linear regression analysis between the increase in visual responses to incongruent distracters in the $20 \%$ Inc block and the modulation in transient activity in response to incongruent distracters in the rMFG.

\section{Results}

\section{Behavioral results}

Reaction times

We first analyzed the filtering costs as described in the behavioral analysis section of the Materials and Methods to compare RTs to the distracter-absent trials in the Pure blocks with those in the $20 \%$ Inc and $60 \%$ Inc blocks, but these comparisons did not yield a significant difference $\left(t_{(19)}=0.17, p=0.86\right.$, and $t_{(19)}=0.34$, 
A

$20 \%$ Inc block

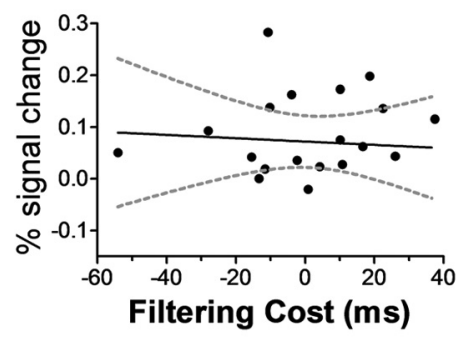

C

$60 \%$ Inc block

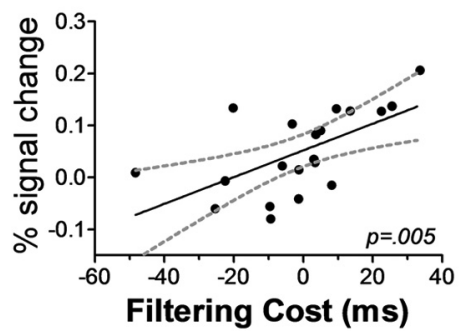

B

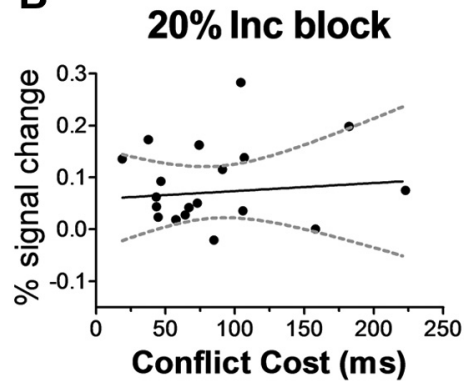

D

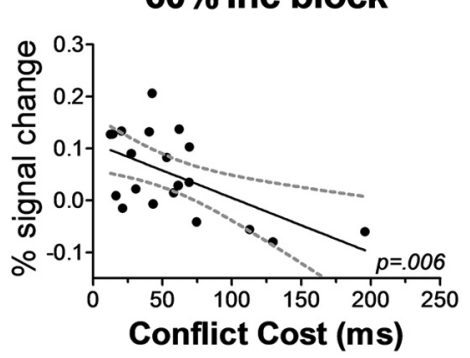

Figure 4. Sustained rMFG activity in $60 \%$ Inc blocks correlates with behavioral measures of filtering and conflict costs. Brainbehavior correlations between sustained activity in rMFG ROI (separately for each type of Mixed block, minus the Pure block activity level in each case) and the magnitude of the Filtering cost (associated with the cognitive effort in suppressing distraction) and the magnitude of the Conflict cost (associated with the processing of incongruent distracters). No brain-behavior interdependencies were observed in the $20 \%$ Inc block $(\boldsymbol{A}, \boldsymbol{B})$. In contrast, in the $60 \%$ Inc block the significant fit of a multiple linear regression model revealed two effects: rMFG activity correlated positively with the Filtering cost $(\boldsymbol{C})$, indicating sustained and proactive effort in attentional control, and inversely with the Conflict cost $(\boldsymbol{D})$, indicating a role of this sustained rMFG engagement in limiting the negative impact of conflicting distraction.

$p=0.73$, respectively; Fig. $2 A$, left graph). A $2 \times 2$ Block Type (20\% Inc, 60\% Inc) by Trial Type (Cong, Inc) ANOVA revealed a significant conflict effect (slowing-down of responses in incongruent versus congruent distracter trials; Fig. 2B, left graph), both in the $20 \%$ Inc blocks (median RTs: 701 and $626 \mathrm{~ms}$, respectively) and in the 60\% Inc blocks (median RTs: $680 \mathrm{~ms} 632 \mathrm{~ms}$, respectively; main effect of Trial Type: $F_{(1,19)}=131.64, p=10^{-9}$ ). Responses were overall slower in the $20 \%$ Inc block relative to the $60 \%$ Inc block $\left(F_{(1,19)}=7.45, p=0.01\right)$. However, the conflict cost was larger in the $20 \%$ Inc block than in the $60 \%$ Inc block (interaction Block type by Trial type: $F_{(1,19)}=30.16, p=10^{-4}$ ). The latter result is consistent with the proportion congruent effect seen in previous studies (Lowe and Mitterer, 1982; Jacoby et al., 2003; Bugg and Crump, 2012; Grandjean et al., 2012; Klein et al., 2014).

To date, the most direct behavioral evidence of proactive distraction filtering (Marini et al., 2013) is that the filtering and the conflict costs were inversely correlated across subjects, suggesting the proactive engagement of distraction filtering led to reduced interference by the incongruent distracters. We therefore tested whether a correlation between filtering and conflict costs was present also in the current study. In the $20 \%$ Inc block, no significant relationship between the filtering and the conflict cost was identified (Fig. 2C, left graph), presumably because the proactive filtering mechanism was only marginally recruited in this type of block. In contrast, in the $60 \%$ Inc block, a significant inverse correlation $\left(r=-0.48\right.$, adjusted $\left.R^{2}=0.19\right)$ between the filtering cost and the conflict cost was found $\left(F_{(1,18)}=5.18, p=0.036\right.$; Fig. 2 , right graph), thus replicating previous findings (Marini et al., 2013). The presence of such correlation can therefore be inter- preted as a signature for the recruitment of a distinct distraction-filtering mechanism in the $60 \%$ Inc block.

The behavioral evidence reported above failed to reveal a significant filtering cost at the group level, an effect previously found in a series of seven experiments investigating this effect (Marini et al., 2013). On the other hand, the correlation analysis demonstrated an inverse relationship between the filtering cost and the conflict cost across participants. Accordingly, we wanted to be reassured that the proactive filtering mechanism was engaged in the present experiment, as in the prior study. One likely possibility as to why the present paradigm failed to reveal a reliable filtering cost at the group level was the much slower pace with which trials followed one another, relative to the previous study. This slower pace was required by the methodological optimization for the fMRI experimental design. Therefore, a control behavioral experiment was conducted to further investigate this aspect, using two different stimulus presentation sequences. The first sequence exactly replicated the timing of the in-scanner sequence, with intertrial intervals (ITIs) being jittered up to $9 \mathrm{~s}$. The second sequence differed only because all ITIs were $1.5 \mathrm{~s}$, giving the much faster pace similar to previous experiments in which filtering costs were observed (Marini et al., 2013). Results showed that with the slow-paced sequence no significant filtering cost was observed $\left(20 \%\right.$ Inc: $t_{(16)}=0.76, p=0.46 ; 60 \%$ Inc: $t_{(16)}=0.97$, $p=0.35)$, whereas with the fast-paced sequence a significant filtering cost emerged ( $20 \%$ Inc: $t_{(13)}=3.17, p=0.008 ; 60 \%$ Inc: $\left.t_{(13)}=6.84, p=0.00002\right)$. The filtering cost has been typically observed in conditions of sustained cognitive effort and therefore it is possible that fluctuations of the cognitive effort in the slowpace experiment led to the lack of a measurable filtering cost, at least at the group level. As regards individual differences, a considerable interindividual variability was observed in the magnitude of the filtering cost ( $60 \%$ Cong block: range -35 to 24 ; and $60 \%$ Inc block: range -38 to 38 ), suggesting not all participants engaged the proactive filtering mechanism to the same extent. For example, the presence of a filtering cost in certain individuals may reflect the recruitment of a proactive distraction-filtering mechanism, whereas the absence of such net cost in other individuals may reflect the predominant use of reactive strategies.

\section{Accuracy}

The overall response accuracy was very high in all distracterabsent conditions (>97\%). No differences in accuracy were observed between distracter-absent conditions in the different types of blocks (Fig. 2 A, right graph). A $2 \times 2$ Block type (20\% Inc, $60 \%$ Inc) by Trial type (Cong, Inc) ANOVA revealed accuracy was higher in congruent as compared with incongruent distracter trials, both in the 20\% Inc blocks (mean Acc: $98.6 \%$ and $93.5 \%$, respectively) and in the $60 \%$ Inc blocks (mean Acc: $98.7 \%$ and 95.1\%, respectively; main effect of Trial type: $F_{(1,19)}=11.9, p=$ 0.002; Fig. $2 B$, right graph). Responses were slightly more accu- 
rate in the $60 \%$ Inc block versus the $20 \%$ Inc block $\left(F_{(1,19)}=6.61, p=0.02\right)$. However, the cost engendered by incongruent distracters in terms of decrease in response accuracy was larger in the $20 \%$ Inc block than in the $60 \%$ Inc block $\left(F_{(1,19)}=\right.$ $8.74, p=0.008$ ), thus paralleling the pattern of results observed for the RTs.

\section{fMRI results}

Proactive control in frontoparietal networks is revealed by sustained activity in Mixed versus Pure blocks

To investigate whether the presence of distraction and conflict modulates proactive control in attention networks, sustained brain activity in the Mixed blocks was compared with sustained brain activity in the Pure blocks. This comparison enabled us to identify sustained brain activations that are enhanced in blocks with both potential and actual distraction compared with completely distracter-free blocks, which would likely include activations reflecting the engagement of proactive filtering mechanisms to better to cope with distraction. Several foci of activation were identified in the frontal, parietal, temporal, and occipital lobe (Table 1). The strongest activations were found in the frontal and parietal cortices (Fig. 3), in regions that have been previously been identified as belonging to the dorsal frontoparietal attention network (Corbetta and Shulman, 2002). In the frontal lobe, we identified bilateral foci in the MFG: on the right in a dorsomedial location and on the left in a somewhat more inferior location. Regions of the right medial frontal gyrus corresponding to Brodmann area 8 (BA 8), the putative location of the human frontal eye field (Paus, 1996; Amiez and Petrides, 2009), were also activated differentially between these block types. Additional foci of differential sustained activity in the frontal lobe localized to the left dorsolateral prefrontal cortex (BA9/46) and the left inferior frontal gyrus (IFG) at the level of the pars opercularis. In the parietal lobe, sustained activations included a cluster in the left superior parietal lobule (SPL), which extended to the adjacent intraparietal sulcus (IPS). Another region of activity was found bilaterally in the precuneus (BA 7). Finally, an additional cluster of activity was isolated in bilateral temporal and occipitotemporal regions, with the highest $Z$ values in the middle temporal gyrus (MTG), in the inferior temporal gyrus, and in the fusiform gyrus (FG).

\section{Functional correlation between rMFG activation and the} behavioral indices of distraction filtering and conflict-related costs attests to proactive distraction filtering

To characterize an anatomical-functional relationship between our behavioral measures of distraction filtering and the activation of the rMFG, we hypothesized that the increased rMFG activation in Mixed blocks might covary with the same two measures that reveal a difference between the two types of Mixed blocks in the behavioral analysis (i.e., the filtering cost and the conflict cost).

To test this hypothesis, sustained activity in the rMFG in the $20 \%$ Inc and in the $60 \%$ Inc block was modeled (separately for each type of block) as a linear function of both the filtering cost and the conflict cost:

\section{$20 \% \operatorname{Inc} \quad 60 \%$ Inc}

Figure 5. Transient responses to incongruent distracter trials are modulated by context. Event-related activity evoked by incongruent distracter trials (minus congruent distracter trials) in the $20 \%$ Inc block and in the $60 \%$ Inc block. In both Mixed blocks, conflicting distracters activated superior frontal and parietal areas. In the $20 \%$ Inc block, incongruent distracters also activated the MFG, the medial frontal cortex (MeFC), and the inferior parietal cortex (IPC) bilaterally.

$$
y_{\mathrm{rMFG}}=\beta_{0}+\beta_{\mathrm{FILT}} x_{1}+\beta_{\mathrm{INC}} x_{2}+\varepsilon
$$

where $y_{\mathrm{rMFG}}$ represents sustained brain activity levels in the rMFG ROI, $\beta_{\text {FILT }}$ is the parameter for the filtering cost variable $\left(x_{1}\right)$, $\beta_{\text {INC }}$ is the parameter for the conflict cost variable $\left(x_{2}\right), \beta_{0}$ is the constant term, and $\varepsilon$ is the error term. In the $20 \%$ Inc block, in line with our prediction of observing no brain-behavior evidence for proactive filtering in blocks with rare distracters, the model fit was not significant $\left(F_{(2,17)}=0.089, p=0.91\right)$, and thus no correlation between brain and behavioral measures could be identified (Fig. $4 A, B$ ). In contrast, the analyses from the $60 \%$ Inc block showed that the model was highly successful at fitting the data (adjusted $\left.\left.R^{2}=0.52 ; F_{(2,17)}=11.1, p=0.0008\right)\right]$. Univariate significance testing revealed that in the $60 \%$ Inc blocks both of the cost-related model parameters, $\beta_{\mathrm{FILT}}$ and $\beta_{\mathrm{INC}}$, reached statistical $\operatorname{significance}\left(F_{(1,17)}=8.59, p=0.009\right.$, and $F_{(1,17)}=7.97, p=0.01$, respectively), with estimated parameter values of $\beta_{\mathrm{FILT}}=0.484$ and $\beta_{\mathrm{INC}}=-0.466$, respectively (Fig. $4 C, D$ ). These values demonstrate the existence of a positive correlation in the $60 \%$ Inc blocks between the filtering cost and the activity in rMFG and an inverse correlation between the conflict cost and the activity in rMFG. Accordingly, in contrast to the $20 \%$ Inc blocks, in the $60 \%$ Inc blocks the proactive effort in attentional control was associated both with an increase in the behavioral measure of distraction filtering and with a reduction of the behavioral interference from conflicting distracters. Thus, these data suggest that in the $60 \%$ Inc blocks the rMFG played a role in orchestrating the implementation of proactive mechanisms of distraction filtering to mitigate distracter-related interference.

\section{Rare conflict reactively activates the frontoparietal cortex more} widely and intensely than does frequent conflict

The above results indicate that contexts with frequent distraction tend to engage brain mechanisms for the proactive filtering of distracting information, and that this engagement leads to a filtering cost, but with the benefit of reduced distracter-related interference. A logical question then becomes how the brain deals with actual distracting input in a reactive fashion in contexts 
Table 2. Peaks of transient activity evoked in incongruent distracter trials minus congruent distracter trials in the $60 \%$ Cong and in the $60 \%$ Inc block

\begin{tabular}{|c|c|c|c|c|c|c|c|c|}
\hline CL-size & $C L-p$ & $Z$ value & $X$ & $Y$ & Z & Side & Region & Area \\
\hline \multicolumn{9}{|l|}{$60 \%$ Cong } \\
\hline 13075 & $<10^{-10}$ & 6.72 & 40 & 36 & 24 & $\mathrm{R}$ & Medial frontal gyrus & BA 9 \\
\hline 13075 & $<10^{-10}$ & 6.54 & 28 & -4 & 48 & $\mathrm{R}$ & Medial frontal gyrus & BA 6 \\
\hline 13075 & $<10^{-10}$ & 6.11 & 50 & 6 & 36 & $\mathrm{R}$ & Precentral gyrus & BA 6 \\
\hline 13075 & $<10^{-10}$ & 5.87 & 6 & 12 & 46 & $\mathrm{R}$ & Medial frontal gyrus & BA 32 \\
\hline 27890 & $<10^{-17}$ & 7.75 & 42 & -44 & 44 & $\mathrm{R}$ & Inferior parietal lobule & BA 40 \\
\hline 27890 & $<10^{-17}$ & 7.42 & 28 & -62 & 46 & $\mathrm{R}$ & Superior parietal lobule & BA 7 \\
\hline 27890 & $<10^{-17}$ & 6.74 & 28 & -66 & 36 & $\mathrm{R}$ & Precuneus & BA 7 \\
\hline 27890 & $<10^{-17}$ & 6.57 & 52 & -56 & -10 & $\mathrm{R}$ & Frontal gyrus & BA 37 \\
\hline 1591 & $<0.05$ & 4.41 & -42 & 24 & 34 & $\mathrm{~L}$ & Precentral g & BA 9 \\
\hline 1591 & $<0.05$ & 4.05 & -44 & 52 & 6 & $\mathrm{~L}$ & Medial frontal gyrus & BA 10 \\
\hline 1591 & $<0.05$ & 3.4 & -20 & 46 & 12 & $\mathrm{~L}$ & I frontal gyrus & BA 9 \\
\hline 1591 & $<0.05$ & 3.32 & -26 & 58 & -6 & $\mathrm{~L}$ & Superior frontal gyrus & BA 10 \\
\hline \multicolumn{9}{|l|}{$60 \% \operatorname{lnc}$} \\
\hline 4933 & $<10^{-4}$ & 5.19 & 16 & 0 & 70 & $\mathrm{R}$ & Superior frontal gyrus & BA 6 \\
\hline 4933 & $<10^{-4}$ & 5.44 & 12 & -46 & 64 & $\mathrm{R}$ & Precuneus & BA 7 \\
\hline 4933 & $<10^{-4}$ & 5.43 & 22 & -44 & 68 & $\mathrm{R}$ & Superior parietal lobule & BA 7 \\
\hline 3113 & $<0.01$ & 4.5 & 56 & -28 & 32 & $\mathrm{R}$ & parietal lobule & BA 40 \\
\hline 3113 & $<0.01$ & 4.49 & 54 & -44 & 16 & $\mathrm{R}$ & Superior temporal gyrus & BA 13 \\
\hline 3113 & $<0.01$ & 3.94 & 46 & -60 & -6 & $\mathrm{R}$ & Middle temporal gyrus & BA 37 \\
\hline 1469 & $<0.05$ & 3.65 & -58 & -2 & 28 & $\mathrm{~L}$ & Precentral gyrus & BA 6 \\
\hline 2879 & $<0.01$ & 5.36 & -40 & -72 & 14 & $\mathrm{~L}$ & Middle occipital gyrus & BA 19 \\
\hline 2879 & $<0.01$ & 4.25 & -14 & -76 & 36 & $\mathrm{~L}$ & Cuneus & BA 7 \\
\hline 4933 & $<10^{-4}$ & 5.14 & -8 & -46 & 64 & $\mathrm{~L}$ & Precuneus & BA 7 \\
\hline 4933 & $<10^{-4}$ & 4.97 & -14 & -42 & 64 & $\mathrm{~L}$ & Precuneus & BA 7 \\
\hline 1469 & $<0.05$ & 4.02 & -50 & -32 & 34 & $\mathrm{~L}$ & Inferior parietal lobule & BA 40 \\
\hline
\end{tabular}

Cluster size (CL-size) is expressed in voxels and the reported $p$ values are FWER-corrected with the cluster method $(\mathrm{CL}-\mathrm{p})$. Coordinates are in MNI space and BA labels refer to the nearest grey matter (within $5 \mathrm{~mm}$ of the peak coordinates).

where conflicting information is not very probable and thus proactive filtering mechanisms would be less engaged (Appelbaum et al., 2014). To study brain mechanisms for reacting to conflicting distracter stimuli in contexts with low versus high-frequency of conflict, we contrasted event-related activity evoked on incongruent-distracter trials with activity evoked on congruentdistracter trials, separately for the two types of Mixed blocks (20\% Inc and 60\% Inc; Fig. 5). Because sensory stimulation was equivalent for the congruent-distracter and incongruentdistracter stimuli, any differences in brain activations between these conditions can be reasonably interpreted as reflecting conflict detection and/or adjustments to conflict. Accordingly, we also conducted a direct comparison of the brain responses to conflict trials in the $20 \%$ Inc versus those in the $60 \%$ Inc block. In both types of Mixed blocks, conflicting distracter stimuli elicited bilateral activations in the SPL and inferior parietal lobule, in the precuneus, and in the precentral gyrus. In addition, brain activity associated with incongruent distracters in the $60 \%$ Inc blocks was globally less extended than in the $20 \%$ Inc block (Tables 2, 3). The direct comparison of responses to conflict in the $20 \%$ Inc versus the $60 \%$ Inc block revealed greater activations in the $20 \%$ Inc block in the frontal (bilateral MFG, right medial frontal gyrus) and inferior temporoparietal cortex. These results indicate that transient brain responses to incongruency were stronger and extended to a wider set of regions (including the right medial frontal gyrus) in blocks where conflicting stimuli occur less frequently.

Reactive responses to conflict in ACC, insula, and rMFG are modulated by context

The results of the whole-brain analysis presented in the previous section indicate a greater reactive recruitment of frontoparietal
Table 3. Peaks of transient activity evoked in incongruent distracter trials (minus congruent distracter trials) in the $60 \%$ Cong block contrasted with the $60 \%$ Inc block

\begin{tabular}{lllrrrlll}
\hline CL-size & CL-p & Z value & $X$ & $Y$ & $Z$ & Side & Region & Area \\
\hline 13427 & $<10^{-6}$ & 6.74 & -32 & -6 & 48 & $\mathrm{~L}$ & Medial frontal gyrus & BA 6 \\
13427 & $<10^{-6}$ & 6.08 & 4 & 10 & 46 & $\mathrm{R}$ & Medial frontal gyrus & BA 32 \\
13427 & $<10^{-6}$ & 6.81 & 30 & -4 & 56 & $\mathrm{R}$ & Medial frontal gyrus & BA 6 \\
13427 & $<10^{-6}$ & 6.16 & 44 & 0 & 38 & $\mathrm{R}$ & Precentral gyrus & BA 6 \\
13427 & $<10^{-6}$ & 5.74 & 18 & 4 & 66 & $\mathrm{R}$ & Superior frontal gyrus & BA 6 \\
27214 & $<10^{-10}$ & 6.28 & -44 & -40 & 36 & $\mathrm{~L}$ & Supramarginal gyrus & BA 40 \\
27214 & $<10^{-10}$ & 6.42 & 36 & -40 & 44 & $\mathrm{R}$ & Inferior parietal lobule & BA 40 \\
27214 & $<10^{-10}$ & 6.38 & 26 & -70 & 30 & $\mathrm{R}$ & Precuneus & BA 31 \\
27214 & $<10^{-10}$ & 6.44 & 48 & -58 & -8 & $\mathrm{R}$ & Frontal gyrus & BA 37 \\
27214 & $<10^{-10}$ & 6.45 & 56 & -44 & 18 & $\mathrm{R}$ & Superior temporal gyrus & BA 13 \\
13427 & $<10^{-10}$ & 6.74 & -32 & -6 & 48 & $\mathrm{~L}$ & Medial frontal gyrus & BA 6 \\
\hline
\end{tabular}

Cluster size (CL-size) is expressed in voxels and the reported $p$ values are FWER-corrected with the cluster method $(\mathrm{CL}-\mathrm{p})$. Coordinates are in MNI space and BA labels refer to the nearest grey matter (within $5 \mathrm{~mm}$ of the peak coordinates).

regions in response to incongruent distracter trials in the $20 \%$ Inc block compared with those in the $60 \%$ Inc block, i.e., when response-conflict interference occurs infrequently as opposed to more frequently. To characterize in greater detail the reactive response to incongruent distracters and its modulation depending on context, we conducted an ROI analysis of conflict-related activity (see Materials and Methods) within the conflict-activated areas of the ACC, insula, and rMFG, with the expectation that we would observe stronger differential activations within each of these for incongruent (versus congruent) distracter trials in the $20 \%$ Inc block versus in the $60 \%$ Inc block. In line with our hypothesis, these ROI analyses revealed stronger differential activations in all of these specific areas for the incongruent versus congruent distracter trials in the $20 \%$ Inc block relative to the $60 \%$ Inc block (Fig. 6). More specifically, after correction for multiple-comparisons (Holm-Bonferroni method; Holm, 1979), this pattern was significant in the ACC, insula, and rMFG (respectively: $t_{(19)}=2.05, p=0.027$, corrected- $\alpha=0.025 ; t_{(19)}=$ $1.83, p=0.042$, corrected- $\alpha=0.05 ; t_{(19)}=2.53, p=0.010$, corrected- $\alpha=0.017)$. In a related set of analyses, it was observed that responses to incongruent distracter trials in the $20 \%$ Inc block were significantly greater than responses to congruent distracter trials in all of these ROIs (ACC: $t_{(19)}=6.09, p<0.001$; insula: $t_{(19)}=4.63, p<0.001$; rMFG: $\left.t_{(19)}=4.09, p<0.001\right)$. In contrast, responses in the $60 \%$ Inc block to incongruent distracter trials were only marginally greater than responses to congruent distracter trials in the ACC and in the insula, and no differences were observed between congruent and incongruent distracter trials in the rMFG (respectively: $t_{(19)}=2.3, p=0.03$, corrected- $\alpha=0.017 ; t_{(19)}=1.78, p=0.09$, corrected- $\alpha=0.025$; $t_{(19)}=0.27, p=0.79$, corrected- $\left.\alpha=0.05\right)$. Together, these results indicate stronger conflict effects in the context with rare (compared with frequent) conflict and attest to context-dependent modulations of responses to incongruent distracters.

Context modulates target responses in the occipitoparietal cortex in the absence of distraction

One key feature of the current study is that it allowed the comparison between transient brain responses evoked by an identical sensory stimulus across different contexts. This approach enabled us to reveal modulations of brain activity that depend on the context but are manifested at the event level. Further analyses along these lines compared brain responses to the simple distracter-absent trials (the targets shown in isolation) between Pure and Mixed blocks. Distracter-absent trials in the Mixed 
A

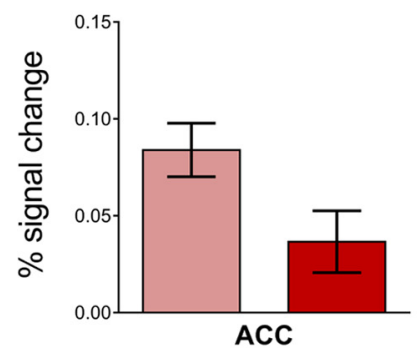

B

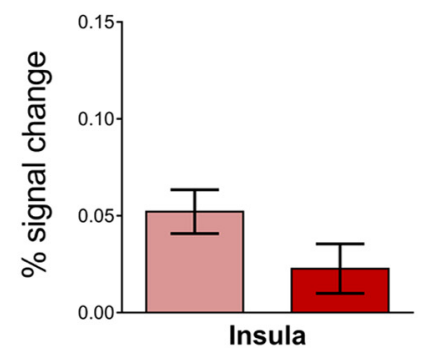

C

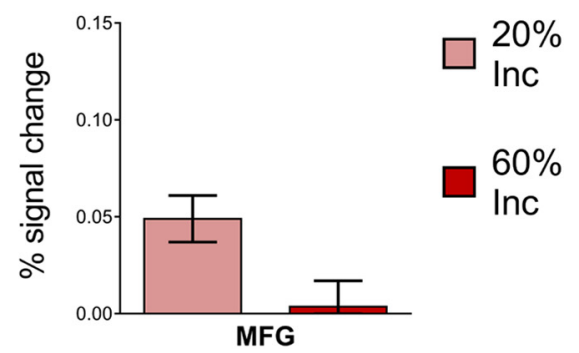

Figure 6. ROI analysis of reactive control shows context-dependent modulations in the ACC, insula, and rMFG. Responses to incongruent minus congruent distracter trials in these three regions of interest. Incongruent distracters elicited stronger activations in the $20 \%$ Inc blocks compared with the $60 \%$ Inc blocks in the ACC (A), insula (B), and rMFG ( $)$. In the ACC and in the insula, incongruent trials elicited stronger responses than congruent trials in both types of Mixed blocks, whereas in the rMFG this was the case only in the $20 \%$ Inc block.

Table 4. Global and local peaks of activity for distracter-absent trials in Mixed blocks contrasted with distracter-absent trials in Pure blocks

\begin{tabular}{lllllllll}
\hline CL-size & CL-p & Z value & $X$ & $Y$ & $Z$ & Side & Region & Area \\
\hline 2272 & $<0.05$ & 4.25 & 26 & -62 & 38 & $\mathrm{R}$ & Precuneus & BA 7 \\
2272 & $<0.05$ & 3.9 & 32 & -80 & 20 & $\mathrm{R}$ & Middle occipital gyrus & BA 19 \\
2272 & $<0.05$ & 3.48 & 42 & -72 & 14 & $\mathrm{R}$ & Middle occipital gyrus & BA 19 \\
2272 & $<0.05$ & 3.2 & 32 & -84 & 8 & $\mathrm{R}$ & Middle occipital gyrus & BA 18 \\
3995 & $<0.01$ & 4.93 & -26 & -72 & 30 & $\mathrm{~L}$ & Precuneus & BA 31 \\
3995 & $<0.01$ & 4.8 & -32 & -54 & 40 & $\mathrm{~L}$ & Angular Gyrus & BA 39 \\
3995 & $<0.01$ & 4.26 & -22 & -72 & 52 & $\mathrm{~L}$ & Superior parietal lobule & BA 7 \\
3995 & $<0.01$ & 3.97 & -10 & -72 & 44 & $\mathrm{~L}$ & Precuneus & BA 7 \\
\hline
\end{tabular}

Cluster size (CL-size) is expressed in voxels and the reported $p$ values are FWER-corrected with the cluster method $(\mathrm{CL}-\mathrm{p})$. Coordinates are in MNI space and BA labels refer to the nearest grey matter (within $5 \mathrm{~mm}$ of the peak coordinates).

blocks minus those in the Pure blocks elicited greater activation in a set of adjacent regions in bilateral posterior parietal and occipital cortices, including the left and right precuneus, the left angular gyrus, the left superior parietal lobule, and the right middle occipital gyrus. A summary of peak activations for this Mixed minus Pure contrast on distracter-absent trials is reported in Table 4 and represented in Figure 7. In contrast, the opposite comparison (Pure minus Mixed blocks) did not yield any significant activation.

These findings reveal previously unidentified modulations of event-related activity (in response to identical sensory stimuli) that critically depend on the probability of conflicting distraction at the context level. These modulations of activation in posterior parietal and occipital cortex suggest an increase in attentional engagement and focusing onto the target stimuli in contexts where these stimuli are likely to be flanked by conflicting distracters.

Proactive distraction filtering in blocks with frequent conflict leads to greater event-related distracter suppression in visual cortex

Conversely to the above analyses of target processing, we also hypothesized that sensory responses in visual cortex to the flanking distracters would be relatively suppressed in the $60 \%$ Inc block compared with the $20 \%$ Inc block, due to the proactive distraction filtering mechanism. The analyses showed that various contiguous regions of the visual cortex responded more to distracter stimuli in the $20 \%$ Inc block than in the $60 \%$ Inc block (Fig. 8A). These areas included bilateral primary visual cortex, bilateral ventral regions in extrastriate visual cortex (V2, V3), left ventral V4, and left lateral occipital complex (LOC). Conversely, the contrast $60 \%$ Inc minus $20 \%$ Inc block did not reveal any significant positive activation. Because these results show that the sensory responses to distracters was relatively stronger in the 20\% Inc block than in the $60 \%$ Inc block, they fit with the hypothesis above, namely there being greater distracter suppression in blocks with a higher probability of conflicting distracters.

\section{The interplay between V3/V4 and rMFG indexes reactive} adjustments in control

Last, a correlation analysis was conducted to examine whether there was a relationship across subjects between sensory modulations of distracter-stimuli processing in the visual cortex and adjustments in attentional control in the rMFG. Neural measures of the increase in the reactive response to incongruency in the $20 \%$ Inc block were correlated across-subjects between the visual cortex and rMFG (Fig. 8B). Subjects who showed increased responses to incongruent distracters in the left V3/V4 also showed increased activity in the $\operatorname{rMFG}\left(F_{(1,18)}=7.26, p=0.01\right.$, adjusted $\left.R^{2}=0.287\right)$. Because this analysis is of the responses to the incongruent-distracter trials, it seems likely to reflect a reactive component of the response to conflict.

\section{Discussion}

We used hybrid block/event-related fMRI to investigate proactive and reactive distraction-filtering mechanisms. Converging brain-behavior evidence showed that attentional control processes in frontoparietal cortex, with a functional hub in rMFG, were invoked in contexts with potential distraction to help filter out conflicting stimuli. Proactive control processes were activated in dorsal frontoparietal cortex, particularly in frequent conflict contexts, whereas reactive control processes were invoked in medial frontal and insular cortex when conflict was rare. When control regions engaged filtering mechanisms, modulations of targetand distracter-related sensory-evoked activity were observed in occipitoparietal cortex consistent with enhanced attentional engagement toward targets and attenuated sensory responses to distracters, respectively.

\section{Potential distraction engages the frontoparietal network proactively}

Sustained frontoparietal attention network activations (Posner and Petersen, 1990; Corbetta and Shulman, 2002) were observed when distracting flankers occurred frequently (Mixed blocks) compared with blocks without distracting flankers (Pure blocks). The dorsolateral frontal regions of this network are thought to coordinate the maintenance of task goals and attentional control (Miller and Cohen, 2001; Reynolds and Chelazzi, 2004), and parietal regions to modulate visual attention (Hopfinger et al., 2000; Kastner and Ungerleider, 2000). We observed the proactive implementation of top-down attentional-control mechanisms invoked in the face of distraction-taxed cognitive brain systems relative to situations without distraction, paralleling the behav- 


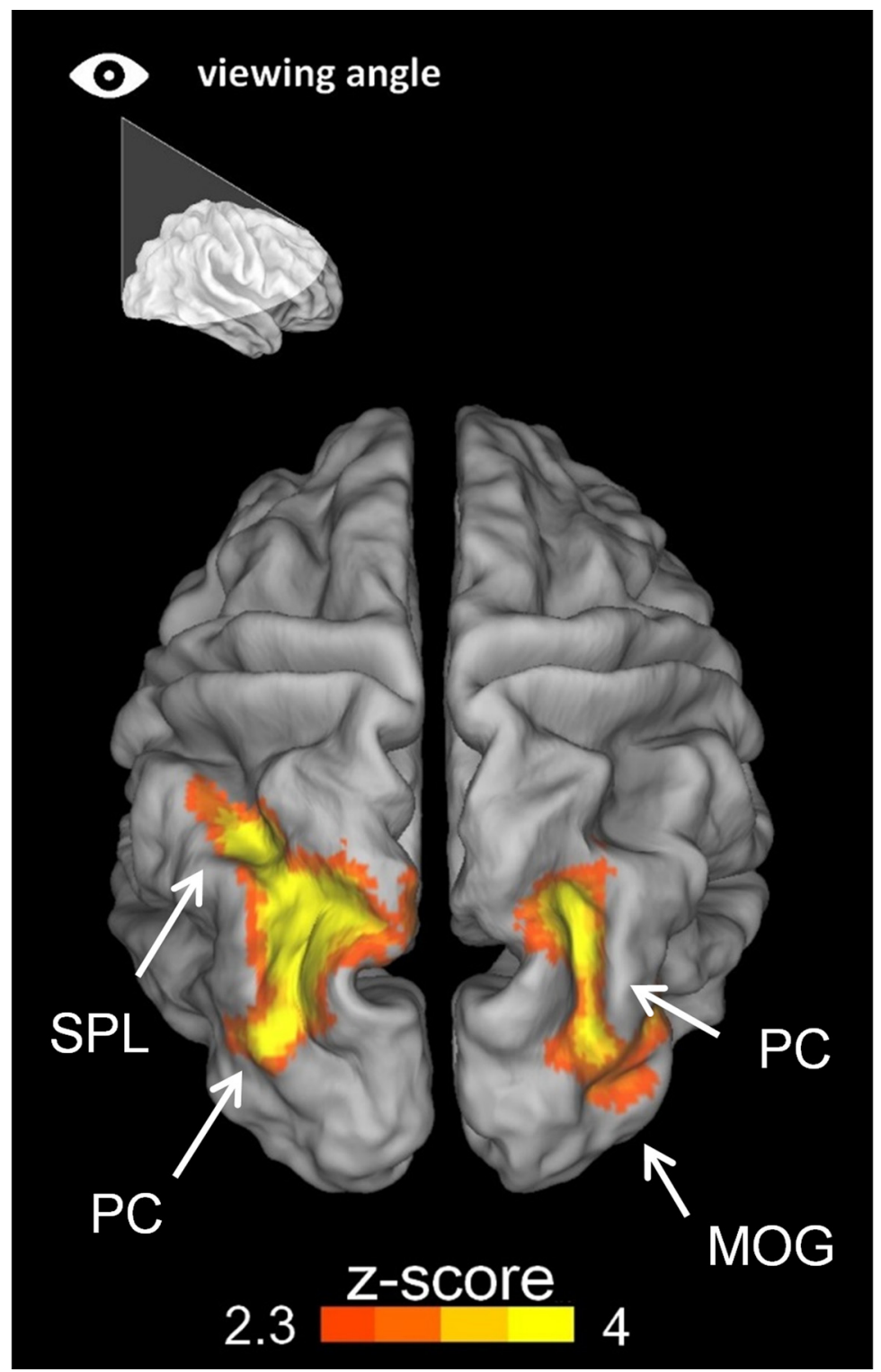

Figure 7. Context-driven potential for distraction modulates occipitoparietal activity in absence of distraction. Transient activity evoked by distracter-absent (target alone) trials in the Mixed blocks minus distracter-absent (target alone) trials in the Pure block. This contrast reflects context-driven differences in the transient response to the very same distracter-absent stimuli (i.e., single target arrows). Two large clusters of activation were observed bilaterally in parietal and occipital regions for this contrast. Peaks were found in the right middle occipital gyrus (MOG), in the right and in the left precuneus (PC), and in the left SPL.

ioral RT slowing, while also showing individual differences (Lavie, 2005; Sarter et al., 2006; Marini et al., 2013).

\section{Frequent conflicting distracters engage proactive distraction filtering in $\mathrm{rMFG}$}

In $60 \%$ Inc blocks, but not in $20 \%$ Inc blocks, sustained rMFG activity strongly correlated with the linear combination of the behavioral filtering cost and conflict cost. The filtering cost correlated directly with sustained rMFG activation, suggesting that rMFG implements sustained-attention processes governing performance in the face of distraction. The conflict cost correlated inversely with sustained rMFG activation, suggesting enhanced control by rMFG effectively limits the negative impact of conflicting distracters on performance. These results thus attest to the rMFG playing a key role in distraction filtering.
A resting-state connectivity study (Fox et al., 2006) previously identified an $\mathrm{rMFG}$ region potentially controlling and regulating both top-down and bottom-up attention networks (Corbetta et al., 2008; Japee et al., 2015). Moreover, previous work suggested sustained rMFG activation might reflect the ongoing effort for maintaining attention during distraction (Demeter et al., 2011), as well as when trying to protect working memory from distracter interferences (Sakai et al., 2002; McNab and Klingberg, 2008). The current study expands our understanding of rMFG's role by demonstrating this region controls a neural mechanism of proactive distraction filtering with a distinct impact on behavior.

Rare conflicting distracters activate the $\mathrm{ACC}$ and insula and trigger reactive control in the rMFG

In line with predicted reduced eventrelated responses to incongruent distracter stimuli in the $60 \%$ Inc blocks due to ongoing proactive control and increased responses to those stimuli in the $20 \%$ Inc blocks due to reactive control, we observed stronger and spatially broader activations to incongruent distractors in the $20 \%$ Inc blocks compared with the $60 \%$ Inc blocks. Moreover, ROI analyses showed greater responses to incongruent distracters in the $20 \%$ Inc versus $60 \%$ Inc blocks in the ACC, insula, and rMFG. The ACC and insula are typically activated during incongruent (vs congruent) trials in flanker tasks (Wager et al., 2005; Nee et al., 2007) and are important for detecting salient and infrequent events (Menon and Uddin, 2010), such as the incongruent distracters in the $20 \%$ Inc block. Accordingly, the ACC activation for incongruent distracters likely relates to the detection and/or monitoring of rare and salient conflict events (Botvinick et al., 2004), whereas the rMFG activation may drive reactive adjustments of control and attention (Durston et al., 2003).

Target responses in the parietal cortex are enhanced in blocks with distracters

A novel aspect of this work is the distraction-context manipulation paradigm, which enabled us to individuate bilateral occipitoparietal regions showing greater transient (i.e., event-related) activations for targets in distracter-absent trials of Mixed (vs Pure) blocks. These regions overlapped with regions showing enhanced sustained activity throughout Mixed (vs Pure) blocks. Accordingly, we argue that transient parietal activity is similar in nature to the sustained activity found in dorsal parietal regions during Mixed (vs Pure) blocks and likely relates to attention processes (Ruff and Driver, 2006). Although sustained activity likely 

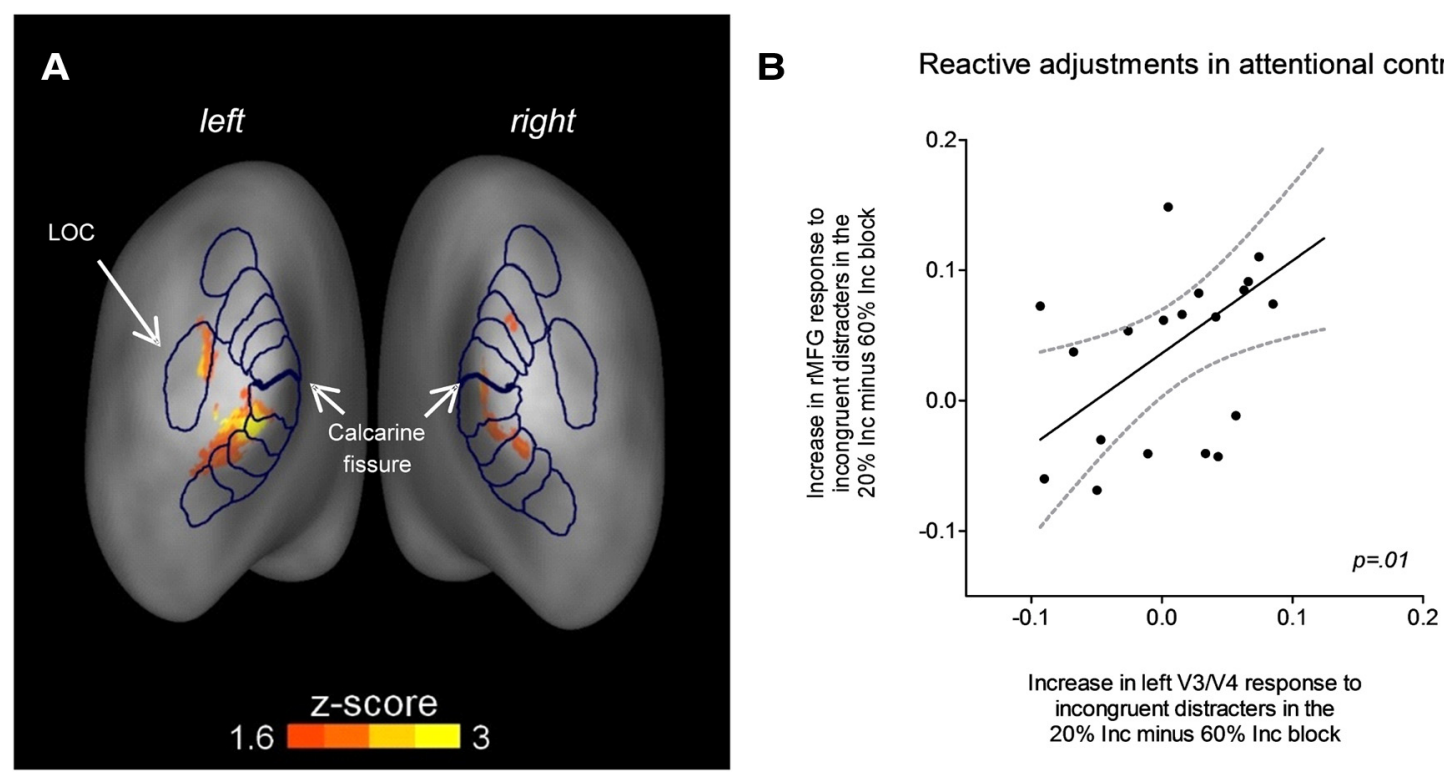

Figure 8. Visual cortex activity reflects modulations of distracter suppression driven by conflict probability and correlates with reactive adjustments in attentional control in the frontal cortex. $A$, Event-related brain activity evoked by distracter-present trials in retinotopic regions of the visual cortex that spatiotopically represent distracters (as identified by "distracter $>$ target" contrast in the functional localizer run). The contrast "distracter $>$ target in $20 \%$ Inc blocks versus in $60 \%$ Inc blocks" is represented here. Several regions of the visual cortex, including ventral V1, V2, V3, and left LOC, showed greater activity in response to distracter stimuli (both congruent and incongruent) in the $20 \%$ Inc block compared with the $60 \%$ Inc block, consistent with there being relatively greater proactive suppression in the latter. $\boldsymbol{B}$, Average response to incongruent distracter stimuli (minus congruent) was extracted from the V3/V4 ROI and from the rMFG ROI, separately for the 20\% Inc block and for the $60 \%$ Inc block. The increase in interference due to rarity of conflict was calculated within each ROI by subtracting values relative to the $60 \% \mathrm{Inc}$ block from those relative to the $20 \%$ Inc block. The graph shows that subjects exhibiting increased interference in the visual ROI also exhibited an increase of activity in the rMFG.

reflected tonic attentional engagement and distraction filtering in frequent-distraction contexts, the transient target-evoked activity observed on distracter-absent trials of Mixed (vs Pure) blocks suggests attentional engagement also reignites whenever any stimulus is displayed during blocks with distraction and conflict, even for no-distraction trials in those blocks.

\section{Distraction filtering suppresses distracter responses in occipital cortex}

A final question we addressed was whether engaging distractionfiltering mechanisms in $60 \%$ Inc blocks would modulate sensory activity for distracter stimuli. Early attention-related effects occur in low-level visual cortex (Desimone and Duncan, 1995; Shulman et al., 1997), and in LOC for stimuli of specific shapes (Murray and Wojciulik, 2003; Stokes et al., 2009). Some of these effects, identified with both fMRI (Serences et al., 2004; Ruff and Driver, 2006; Kelley et al., 2013) and EEG (Kelly et al., 2006; Sawaki et al., 2012; Gaspar and McDonald, 2014), specifically attest to distracter suppression. However, previous studies have not investigated within the same experiment both control processes and sensory-related effects of attention with mixed-design fMRI (i.e., sustained and event-related), nor whether sensory modulations of distracters depend on the context-level probability of conflict. The current study helps fill these gaps.

Event-related responses to incongruent distracters in the visual cortex were reduced in the $60 \%$ Inc blocks, which were also characterized by increased sustained activity in rMFG. These results support the existence of a distraction-filtering mechanism that is engaged in rMFG in contexts with frequent conflict and that serves to mitigate sensory responses to distracters presented at predictable spatial locations (Gouws et al., 2014). Moreover, we found that subjects with the strongest event-related visual-cortex responses to rare (vs frequent) conflicting distracters implemented the largest reactive attentional-control activity in the rMFG.
Our study highlights the contextual dependency of attentional control and sensory processing of distracters and complements previous results on the selective enhancement of sensory representations of targets in the presence of distracters (Feredoes et al., 2011; Kelley et al., 2013). A related aspect regards the nature (proactive or reactive) of this distracter suppression. In principle, reduced evoked distracter-stimulus responses in $60 \%$ Inc blocks (vs 20\% Inc blocks) might reflect either a proactive effort to prevent distraction by the distracter stimuli or a reactive suppression of the sensory responses to distracters. Although fMRI does not have the necessary time resolution to distinguish these possibilities, the additional exploratory post hoc analysis hints at a proactive nature of the suppression since distracter responses were suppressed for both incongruent and congruent trials. Because congruent trials elicit no conflict, it seems plausible to assume that there should be no need to suppress them reactively and that proactive suppression is more likely.

\section{Conclusions: integrating conflict detection with attentional control}

The conflict monitoring system (Botvinick et al., 2004) and the frontoparietal attention network (Corbetta and Shulman, 2002; Woldorff et al., 2004) play a major role in coordinating and guiding behavior. Conflict studies and attention studies have sometimes used the same experimental paradigms (i.e., flanker or Stroop tasks); however, interactions between the two systems have not been extensively investigated. A recent study (Walsh et al., 2011) characterized interactions between a cognitive-control area (ACC) and the frontoparietal attention network, finding conflict on a given trial was associated with increased ACC activation on that trial and increased frontoparietal activation on the subsequent trial, consistent with the ACC monitoring conflict and subsequently engages attentional control regions (Botvinick et al., 1999, 2004; Carter et al., 2000; Casey et al., 2000). Here, we 
show both proactive (sustained) and reactive (event-related) modulations of attention-related dynamics in rMFG. First, in Mixed blocks sustained activation of rMFG increased, likely indicating a proactive effort in sustaining attention and control due to the frequent presence of distraction and conflict. Second, the sustained rMFG activations in the $60 \%$ Inc blocks correlated across subjects with behavioral distraction filtering measures, attesting to a role for this region in exerting proactive control over frequent distracters. Third, incongruent distracter trials transiently activated the rMFG only in the $20 \%$ Inc blocks, likely indicating reactive modulations of attentional control that were less necessary under the proactive filtering processing instantiated in the $60 \%$ Inc blocks.

Together, our results attest to different patterns of responses to conflicting distracters and to different adjustments in control depending on the probability of conflict. Rare conflicting distracters (in the $20 \%$ Inc block) are dealt with mainly when they occur (i.e., with reactive dynamics), through transient signals in the insula and ACC that call for a re-instantiation of attentional control in rMFG. Complementarily, contexts with frequent conflicting distracters (i.e., in the $60 \%$ Inc block) proactively engage the same rMFG control region. The control exerted by rMFG then influences attentional orienting to targets in the parietal cortex and sensory responses to distracters in visual cortex, with an attenuation of distracter-related activity when distractors are likely. These findings thus clarify the brain's orchestration of detecting and responding to conflicting distraction and provide evidence for a specific distraction-filtering mechanism that is proactively instantiated in the $\mathrm{M} M \mathrm{FG}$ when frequent distraction is foreseen, leading to top-down modulation of target-related and distracter-related activity in occipitoparietal cortex.

\section{References}

Amiez C, Petrides M (2009) Anatomical organization of the eye fields in the human and non-human primate frontal cortex. Prog Neurobiol 89: 220-230. CrossRef Medline

Appelbaum LG, Boehler CN, Davis LA, Won RJ, Woldorff MG (2014) The dynamics of proactive and reactive cognitive control processes in the human brain. J Cogn Neurosci 26:1021-1038. CrossRef Medline

Aron AR (2011) From reactive to proactive and selective control: developing a richer model for stopping inappropriate responses. Biol Psychiatry 69:e55-e68. CrossRef Medline

Botvinick M, Nystrom LE, Fissell K, Carter CS, Cohen JD (1999) Conflict monitoring versus selection-for-action in anterior cingulate cortex. Nature 402:179-181. CrossRef Medline

Botvinick MM, Cohen JD, Carter CS (2004) Conflict monitoring and anterior cingulate cortex: an update. Trends Cogn Sci 8:539-546. CrossRef Medline

Braver TS (2012) The variable nature of cognitive control: a dual mechanisms framework. Trends Cogn Sci 16:106-113. CrossRef Medline

Braver TS, Paxton JL, Locke HS, Barch DM (2009) Flexible neural mechanisms of cognitive control within human prefrontal cortex. Proc Natl Acad Sci U S A 106:7351-7356. CrossRef Medline

Bugg JM, Crump MJ (2012) In support of a distinction between voluntary and stimulus-driven control: a review of the literature on proportion congruent effects. Front Psychol 3:367. CrossRef Medline

Carter CS, Macdonald AM, Botvinick M, Ross LL, Stenger VA, Noll D, Cohen JD (2000) Parsing executive processes: strategic vs. evaluative functions of the anterior cingulate cortex. Proc Natl Acad Sci U S A 97:1944-1948. CrossRef Medline

Casey BJ, Thomas KM, Welsh TF, Badgaiyan RD, Eccard CH, Jennings JR, Crone EA (2000) Dissociation of response conflict, attentional selection, and expectancy with functional magnetic resonance imaging. Proc Natl Acad Sci U S A 97:8728-8733. CrossRef Medline

Corbetta M, Shulman GL (2002) Control of goal-directed and stimulusdriven attention in the brain. Nat Rev Neurosci 3:201-215. CrossRef Medline

Corbetta M, Patel G, Shulman GL (2008) The reorienting system of the human brain: from environment to theory of mind. Neuron 58:306-324. CrossRef Medline

Dale AM (1999) Optimal experimental design for event-related fMRI. Hum Brain Mapp 8:109-114. CrossRef Medline

Demeter E, Hernandez-Garcia L, Sarter M, Lustig C (2011) Challenges to attention: a continous arterial spin labeling (ASL) study of the effects of distraction on sustained attention. Neuroimage 54:1518-1529. CrossRef Medline

Desimone R, Duncan J (1995) Neural mechanisms of selective visual attention. Annu Rev Neurosci 18:193-222. CrossRef Medline

Durston S, Davidson MC, Thomas KM, Worden MS, Tottenham N, Martinez A, Watts R, Ulug AM, Casey BJ (2003) Parametric manipulation of conflict and response competition using rapid mixed-trial event-related fMRI. Neuroimage 20:2135-2141. CrossRef Medline

Eriksen BA, Eriksen CW (1974) Effects of noise letters upon identification of a target letter in a non-search task. Percept Psychophys 16:143-149. CrossRef

Feredoes E, Heinen K, Weiskopf N, Ruff C, Driver J (2011) Causal evidence for frontal involvement in memory target maintenance by posterior brain areas during distracter interference of visual working memory. Proc Natl Acad Sci U S A 108:17510-17515. CrossRef Medline

Fox J (1997) Applied regression analysis, linear models, and related methods. London: Sage.

Fox MD, Corbetta M, Snyder AZ, Vincent JL, Raichle ME (2006) Spontaneous neuronal activity distinguishes human dorsal and ventral attention systems. Proc Natl Acad Sci U S A 103:10046-10051. CrossRef Medline

Gaspar JM, McDonald JJ (2014) Suppression of salient objects prevents distraction in visual search. J Neurosci 34:5658-5666. CrossRef Medline

Geng JJ (2014) Attentional mechanisms of distractor suppression. Curr Direct Psychol Sci 23:147-153. CrossRef

Geng JJ, Diquattro NE (2010) Attentional capture by a perceptually salient non-target facilitates target processing through inhibition and rapid rejection. J Vis 10(6):5 1-12. CrossRef Medline

Gouws AD, Alvarez I, Watson DM, Uesaki M, Rodgers J, Rogers J, Morland $A B$ (2014) On the role of suppression in spatial attention: evidence from negative BOLD in human subcortical and cortical structures. J Neurosci 34:10347-10360. CrossRef Medline

Grandjean J, D'Ostilio K, Phillips C, Balteau E, Degueldre C, Luxen A, Maquet P, Salmon E, Collette F (2012) Modulation of brain activity during a stroop inhibitory task by the kind of cognitive control required. Plos One 7:e41513. CrossRef Medline

Gulbinaite R, Johnson A, de Jong R, Morey CC, van Rijn H (2014) Dissociable mechanisms underlying individual differences in visual working memory capacity. Neuroimage 99:197-206. CrossRef Medline

Holm S (1979) A simple sequentially rejective multiple test procedure. Scand J Statist 6:65-70.

Hopfinger JB, Buonocore MH, Mangun GR (2000) The neural mechanisms of top-down attentional control. Nat Neurosci 3:284-291. CrossRef Medline

Jacoby LL, Kelley CM, McElree BD (1999) The role of cognitive control: early selection versus late correction. In: Dual-process theories in social psychology (Chaiken S, Trope Y, eds), pp 383-400. New York: Guilford.

Jacoby LL, Lindsay DS, Hessels S (2003) Item-specific control of automatic processes: stroop process dissociations. Psychon Bull Rev 10:634-644. Medline

Japee S, Holiday K, Satyshur MD, Mukai I, Ungerleider LG (2015) A role of right middle frontal gyrus in reorienting of attention: a case study. Front Syst Neurosci 9:23. CrossRef Medline

Jenkinson M, Bannister P, Brady M, Smith S (2002) Improved optimization for the robust and accurate linear registration and motion correction of brain images. Neuroimage 17:825-841. CrossRef Medline

Kastner S, Ungerleider LG (2000) Mechanisms of visual attention in the human cortex. Ann Rev Neurosci 23:315-341. CrossRef Medline

Kelley TA, Rees G, Lavie N (2013) The impact of distractor congruency on stimulus processing in retinotopic visual cortex. Neuroimage 81: 158-163. CrossRef Medline

Kelly SP, Lalor EC, Reilly RB, Foxe JJ (2006) Increases in alpha oscillatory power reflect an active retinotopic mechanism for distracter suppression during sustained visuospatial attention. J Neurophysiol 95:3844-3851. CrossRef Medline

Klein PA, Petitjean C, Olivier E, Duque J (2014) Top-down suppression of 
incompatible motor activations during response selection under conflict. Neuroimage 86:138-149. CrossRef Medline

Kleiner M, Brainard D (2007) What's new in Psychtoolbox-3. Perception 36:14. CrossRef Medline

Lavie N (2005) Distracted and confused? Selective attention under load. Trends Cogn Sci 9:75-82. CrossRef Medline

Leber AB (2010) Neural predictors of within-subject fluctuations in attentional control. J Neurosci 30:11458-11465. CrossRef Medline

Lowe DG, Mitterer JO (1982) Selective and divided attention in a Stroop task. Can J Psychol 36:684-700. CrossRef Medline

Maldjian JA, Laurienti PJ, Kraft RA, Burdette JH (2003) An automated method for neuroanatomic and cytoarchitectonic atlas-based interrogation of fMRI data sets. Neuroimage 19:1233-1239. CrossRef Medline

Marini F, Chelazzi L, Maravita A (2013) The costly filtering of potential distraction: evidence for a supramodal mechanism. J Exp Psychol Gen 142:906-922. CrossRef Medline

Marini F, van den Berg B, Woldorff MG (2015) Reward prospect interacts with trial-by-trial preparation for potential distraction. Vis Cogn 23: 313-335. CrossRef Medline

McNab F, Klingberg T (2008) Prefrontal cortex and basal ganglia control access to working memory. Nat Neurosci 11:103-107. CrossRef Medline

Menon V, Uddin LQ (2010) Saliency, switching, attention and control: a network model of insula function. Brain Struct Funct 214:655-667. CrossRef Medline

Miller EK, Cohen JD (2001) An integrative theory of prefrontal cortex function. Ann Rev Neurosci 24:167-202. CrossRef Medline

Murray SO, Wojciulik E (2003) Attention increases neural selectivity in the human lateral occipital complex. Nat Neurosci 7:70-74. CrossRef Medline

Nee DE, Wager TD, Jonides J (2007) Interference resolution: insights from a meta-analysis of neuroimaging tasks. Cogn Affect Behav Neurosci 7:1-17. CrossRef Medline

Nobre K, Kastner S (eds) (2014) The Oxford handbook of attention. Oxford UP.

Oliveira FT, Hickey C, McDonald JJ (2014) Proactive and reactive processes in the medial frontal cortex: an electrophysiological study. PloS one 9:e84351. CrossRef Medline

Ollinger JM, Shulman GL, Corbetta M (2001) Separating processes within a trial in event-related functional MRI: I. The method. Neuroimage 13: 210-217. CrossRef Medline

Paus T (1996) Location and function of the human frontal eye-field: a selective review. Neuropsychologia 34:475-483. CrossRef Medline

Petersen SE, Dubis JW (2012) The mixed block/event-related design. Neuroimage 62:1177-1184. CrossRef Medline

Posner MI, Petersen SE (1990) The attention system of the human brain. Annu Rev Neurosci 13:25-42. CrossRef Medline

Purmann S, Badde S, Wendt M (2009) Adjustments to recent and frequent conflict reflect two distinguishable mechanisms. Psychon Bull Rev 16: 350-355. CrossRef Medline

R Core Team (2015) R: a language and environment for statistical computing. Vienna: R Foundation for Statistical Computing.

Ratcliff R (1993) Methods for dealing with reaction times outliers. Psychol Bull 114:510-532. CrossRef Medline

Reynolds JH, Chelazzi L (2004) Attentional modulation of visual processing. Ann Rev Neurosci 27:611-647. CrossRef Medline
Ridderinkhof KR, de Vlugt Y, Bramlage A, Spaan M, Elton M, Snel J, Band GP (2002) Alcohol consumption impairs detection of performance errors in mediofrontal cortex. Science 298:2209-2211. CrossRef Medline

Ruff CC, Driver J (2006) Attentional preparation for a lateralized visual distractor: behavioral and fMRI evidence. J Cogn Neurosci 18:522-538. CrossRef Medline

Sakai K, Rowe JB, Passingham RE (2002) Active maintenance in prefrontal area 46 creates distractor-resistant memory. Nat Neurosci 5:479-484. CrossRef Medline

Sarter M, Gehring WJ, Kozak R (2006) More attention must be paid: the neurobiology of attentional effort. Brain Res Rev 51:145-160. CrossRef Medline

Sawaki R, Geng JJ, Luck SJ (2012) A common neural mechanism for preventing and terminating the allocation of attention. J Neurosci 32: 10725-10736. CrossRef Medline

Seidl KN, Peelen MV, Kastner S (2012) Neural evidence for distracter suppression during visual search in real-world scenes. J Neurosci 32: 11812-11819. CrossRef Medline

Serences JT, Yantis S, Culberson A, Awh E (2004) Preparatory activity in visual cortex indexes distractor suppression during covert spatial orienting. J Neurophysiol 92:3538-3545. CrossRef Medline

Shulman GL, Corbetta M, Buckner RL, Raichle ME, Fiez JA, Miezin FM, Petersen SE (1997) Top-down modulation of early sensory cortex. Cereb Cortex 7:193-206. CrossRef Medline

Smith SM, Jenkinson M, Woolrich MW, Beckmann CF, Behrens TE, Johansen-Berg H, Bannister PR, De Luca M, Drobnjak I, Flitney DE, Niazy RK, Saunders J, Vickers J, Zhang Y, De Stefano N, Brady JM, Matthews PM (2004) Advances in functional and structural MR image analysis and implementation as FSL. Neuroimage 23:S208-S219. CrossRef Medline

Stokes M, Thompson R, Nobre AC, Duncan J (2009) Shape-specific preparatory activity mediates attention to targets in human visual cortex. Proc Natl Acad Sci U S A 106:19569-19574. CrossRef Medline

Townsend JT, Ashby FG (1983) Stochastic modelling of elementary psychological processes. Cambridge UP, London, UK.

Van Essen DC (2005) A population-average, landmark- and surface-based (PALS) atlas of human cerebral cortex. Neuroimage 28:635-662. CrossRef Medline

Visscher KM, Miezin FM, Kelly JE, Buckner RL, Donaldson DI, McAvoy MP, Bhalodia VM, Petersen SE (2003) Mixed blocked/event-related designs separate transient and sustained activity in fMRI. Neuroimage 19: 1694-1708. CrossRef Medline

Wager TD, Nichols TE (2003) Optimization of experimental design in fMRI: a general framework using a genetic algorithm. Neuroimage 18: 293-309. CrossRef Medline

Wager TD, Sylvester CY, Lacey SC, Nee DE, Franklin M, Jonides J (2005) Common and unique components of response inhibition revealed by fMRI. Neuroimage 27:323-340. CrossRef Medline

Walsh BJ, Buonocore MH, Carter CS, Mangun GR (2011) Integrating conflict detection and attentional control mechanisms. J Cogn Neurosci 23: 2211-2221. CrossRef Medline

Woldorff MG, Hazlett CJ, Fichtenholtz HM, Weissman DH, Dale AM, Song AW (2004) Functional parcellation of attentional control regions of the brain. J Cogn Neurosci 16:149-165. CrossRef Medline 